\title{
An Uncertain Tale: Alternative Conceptualizations of Pedagogical Leadership
}

\author{
Kim Atkinson and Lexie Biegun
}

Kim Atkinson is an early childhood educator and pedagogical facilitator at the University of Victoria's Unit for Early Years Research and Development. Email: klatkins@uvic.ca

Lexie Biegun is an owner/pedagogical facilitator and visionary leader of Lexie’s Little Bears Child Care Inc. in beautiful Victoria, BC.

This article draws on the experiences of two educators to reimagine traditional framings of pedagogical leadership. In the field of early childhood education, pedagogical leadership carries conflicting conceptualizations and is often associated with an "expert" who will dictate indicators of quality, suggesting certainty and fixed ways of practicing. Educators are often reluctant to take on leadership roles that seem antithetical to their collaborative caring practices. In our work together in the Investigating Quality Project and in using pedagogical narration as a tool for generating critical dialogue, we explore alternative images of pedagogical leadership. Through sharing our stories, we offer a mode of thinking about pedagogical leadership that embraces relationality and uncertainty and invites a culture of dialogue.

Key words: pedagogical leadership; pedagogical narration; critically reflective practice; pedagogical facilitator; culture of dialogue; early childhood education
This article tells a tangled tale of pedagogical leadership. We, Kim and Lexie, are early childhood educators, working in different roles who, with some trepidation, are taking up the term pedagogical leader. Our trepidation is rooted in an unease with pervading images of leadership as something that happens "out there" in government or academia, and with assumed characteristics of leaders as experts that seem antithetical to the collaborative caring practices of the work of early childhood educators. In sharing the tale of our work together, we hope to offer alternative images of pedagogical leadership as grounded in dialogue, situated in daily practice, and always becoming.

\section{A Troubled Tale of Pedagogical Leadership}

Within the landscape of early childhood education, leader is a word alive with contested meanings, a word which educators in the field are often reluctant to own. Multiple and sometimes conflicting conceptions of leadership abound. Traditional understandings of leadership framed within images drawn from the predominately male business world (Woodrow \& Busch, 2009) that imply hierarchical models of power and control (Krieg, Davis, \& Smith, 2014) do not sit well with many early childhood educators.

More specifically, the term pedagogical leadership is fraught with its own troubled conceptualizations. Workshops and professional development sessions are offered by a "pedagogical expert" who offers tips for "quality" child care. Pedagogical leadership is often considered to be the domain of those who work in governmental spheres of policy development or academia who determine what constitutes "best practice." Moreover, pedagogical leadership is conflated with administrative or managerial roles that ensure correct application of rules and procedures (Krieg et al., 2014; Murray \& Clark, 2013) and are often situated within discourses of masculinity (Woodrow \& Busch, 2009).

These dominant conceptualizations of pedagogical leadership place the leader as an expert, someone with the "right knowledge" who has the power to dictate indicators of quality to which others must defer (Murray \& Clark, 
2013; Woodrow \& Busch, 2009). Further, these images of leadership suggest certainty, fixed ways of practicing, and mastery of particular knowledges. Leaders are seen to be charismatic individuals who will take charge and lead the way, ultimately placing leadership in a leader/follower binary, negating possibilities of collective leadership to occur in daily practice (Krieg et al., 2014; Woodrow \& Busch, 2009). While the traditional role of the leader is heavily gendered in masculine discourses, early childhood educators are often positioned as a substitute mother. This gendered maternal image assumes characteristics such as nurturance, care, happiness, and passion (Langford, 2006) that are diametrically opposed to conventional images of leadership, where attributes such as authoritativeness, drive, and assertiveness are valued. In other words, the act of working as an early childhood educator summarily precludes leadership potential.

Broadening the conversation around pedagogical leadership in the early years sector is more urgent than ever as the need for child care expands in Canada (Sinha, 2014). Child care has become the focus of unprecedented political attention as governments create frameworks and policy documents to establish parameters for "quality care" (Canadian Council of Ministers of Education, 2014; Government of Canada, 2017; Government of Ontario, 2017; StrongStart BC Early Learning Programs, 2008). These documents are well intended; some promote ideas of educators as co-learners with children and identify children as competent and full of potential. However, quality programs in these documents remain conflated with modernist understandings of objective "truths" that define best practice to ensure children become the "right" kind of future citizen (Dahlberg \& Moss, 2005; Osgood \& Giugni, 2015; Pacini-Ketchabaw, Nxumalo, Kocher, Elliott, \& Sanchez, 2014). Within these agendas, quality is framed by developmental theories that position children in need of adult intervention to acquire emotional, cognitive, social, and physical skills (Pacini-Ketchabaw et al., 2014). Growth and development is described as linear, with predictable stages that can be applied to all children, universalizing them through concepts of readiness and isolated skill assessment (Osgood \& Giugni, 2015; Pacini-Ketchabaw et al., 2014). These dominant discourses of childhood impose particular ways of thinking about children that deny multiple cultural beliefs, values, and practices (Osgood \& Giugni, 2015). Educators are stripped of the space and opportunity to grapple with complexity, diversity, and other ways of being, doing, and be(com)ing with children (Osgood \& Giugni, 2015). As Osgood and Giugni (2015) tell us, these discourses underpin the idea that "quality remains a quantifiable, recognisable and measurable thing that can be objectively assessed and ultimately attained" (p. 1). As we will describe further, rethinking pedagogical leadership as a situated, collaborative endeavour is critical in challenging these top-down approaches and may offer more localized and diverse perspectives of quality in early childhood spaces.

Despite some of the limiting, managerial perceptions of pedagogical leadership in early childhood education, there is movement to reconceptualize leadership. Early childhood scholars and professional organizations (Berger, 2015; Young, 2007) are working toward imagining different dimensions of early childhood leadership that include activism, collaboration, critical thinking, and a professional identity that embraces plurality. This reimagining opens spaces for leadership to be enacted on the large stage of the public sphere but also, and perhaps more importantly, in the small moments of daily practice. With the hope of contributing to these reimaginings, we offer our imperfect, questioning, and ongoing tale of pedagogical leadership. We share this tale, not to suggest a specific trajectory of pedagogical leadership to be applied elsewhere, but as an invitation to dialogue toward more possible futures in early childhood education.

\section{Working Together in the Investigating Quality Project}

We, Kim and Lexie, began working together within this landscape of competing and contradicting images of pedagogical leadership. We came to this work in positions of leadership; however, our leadership roles were entirely different: Lexie as owner/director of a large, multiage centre and Kim as pedagogical facilitator (pedagogista) 
with the Investigating Quality (IQ) Project at the University of Victoria (Pacini-Ketchabaw \& Pence, 2010). Beginning in 2006, the IQ Project promotes the active engagement of early learning and child care practitioners in discussions that lead to the formation of sustainable and innovative early years environments. The project aims to create communities of practice by engaging practitioners in collaboratively reflecting on their knowledge, values, experiences, and practices and exploring the meanings and practices of quality care (Pacini-Ketchabaw \& Pence, 2010).

In 2011, a second phase of the IQ Project was implemented with the creation of the role of pedagogical facilitators. Facilitators visit child care sites weekly to engage in reflective dialogue, discuss theoretical perspectives, and support new ideas and thinking. Kim, as pedagogical facilitator, began working with Lexie and the educators in her centre in 2013. Kim visits Lexie's centre weekly, bringing questions, different theoretical perspectives, and reflective dialogue. Through ongoing email communication and sharing of resources, we explore possibilities for reconceptualizing early learning and care and critically reflect on quality. Together we think with postfoundational early childhood theorists (Dahlberg \& Moss, 2005; Pacini-Ketchabaw et al., 2014) and challenge taken-forgranted assumptions of what early years practice can be. Once a month, we gather for learning circles with other educators from the community to discuss and reflect on moments of practice collected in pedagogical narrations. Pedagogical narration is a term we use in British Columbia to describe a process of writing, photographing, or documenting moments in the daily lives of children and educators that are then shared to generate critical dialogue and complexify practice (Berger, 2015; Pacini-Ketchabaw, et al., 2014). Pedagogical narration makes daily practices open to interpretation and negotiation and is thus is an important tool to challenge narrow, prescriptive understanding of quality. As educators work and think with pedagogical narrations, they are enacting pedagogical leadership by engaging in democratic politics. Dahlberg and Moss (2005) explain:

Pedagogical documentation makes learning visible: but it goes beyond this and by so doing enters the political sphere, making what is visible subject to interpretation, critique and argumentation. By taking this vital second step, by becoming minor politics, pedagogical documentation can enable dominant discourses to be challenged rather than reinforced, normative frameworks to be transgressed rather than more tightly drawn, governmentality to be undermined rather than applied. (p. 157)

In the next section, we share individual and collective stories of our work that highlight the imperfect, discomfiting moments, as well as the joyful openings that emerged in our explorations as pedagogical leaders.

\section{What Kind of Leader Can I Be?: Lexie}

I'm grappling with a new title: pedagogical leader. I'm feeling raw and open, unworthy of what seems to be (in my eyes) this extremely respected role. I have been an early childhood educator for more than twenty years, and I realized a long time ago that best practice, according to my beliefs of what best practice is, is not typically offered in most settings. In 1997, I opened my first nature-based centre with a clear vision of what I wanted to provide to children and their families. What began as a small program with seven children and one educator has now grown into many larger centres with a total of 57 licenced spaces, 17 amazing educators, and two neighbouring locations. The dreams I have been visualizing are now my reality. With nearly four acres of forest to explore, my nature-based programs are thriving!

Shifting from being an early childhood educator to a director and pedagogical leader feels new and scary. I can feel the shift; I will embrace the pull. My new role is complex and honestly a bit uncomfortable, but I am excited 
by the possibilities. Participation in the IQ Project has allowed me to continue my research as an educator, and has provoked me to ask myself:

Why do I do what I do as an educator? As a leader?

Are there other ways of "being" that I can explore?

How can I inspire a culture of reflective practice?

How do I share my vision with my staff in a way that is uplifting, inspiring, and noninvasive?

\section{Being in Question, Putting into Question: Kim}

My role as a pedagogical facilitator is not to be the expert, to be prescriptive, or to instruct educators on "getting it right." Rather, as Vintimilla (2016) tells us, the pedagogical facilitator's role is to be-in-question and put-intoquestion. In this way, the pedagogical facilitator "tries to pose reverberant questions that open space for educators to put-into-question and, indeed, to put the educators themselves into-question" (p. 4). This concept of putting into question challenges concepts of transferring knowledge in a hierarchical model of learner/knower. Inherent in the idea of putting into question is acknowledgment of the complex nature of the work of early childhood educators, and the idea that daily practice is complicated and intensely relational. Thus, a pedagogical facilitator's role is to engage others in ongoing, dynamic, and transformational dialogue about learning, teaching, and living together. But how might I as an outsider, a stranger, begin dynamic dialogue that might incite complications, questions, and unsettlings? How might I provoke thinking without offending? Is it even possible to provoke without offending?

In 2013 we, Kim and Lexie, began meeting weekly at Lexie's child care setting. Our coming together was resplendent with uncertainty, each of us seeking to know the other. Questions hovered around us as we tentatively stretched the bounds of polite conversation to find spaces of commonality and difference. We were inspired by unspoken questions:

Who are we in this work? Who might we become?

What is possible?

What already exists? What might we bring into existence?

How do we think-be-do with one another?

What are the questions yet to be articulated?

Can we be uncertain, imperfect, uncomfortable in these encounters?

Can the dissensus we will surely be confronted with be generative?

\section{Pedagogical Narration as a Tool for Collaborative Dialogue}

The following describes a moment in which we began to put these questions to work:

Kim, Lexie, and the children step into a small room where walls and floor are draped in swaths of white canvas that glow with sunlight streaming in from a small window. In the centre of the room is a cedar stump upon which sits a large block of clay. This room is new to all of us, having 
undergone a dramatic transformation from the "Zoom Room," where animated posters lined the walls and shelves were filled with tubs of cars and trucks. We are all curious about this new space, this atelier, this canvas, this clay. Lexie and Kim sit against the wall, Lexie with clipboard and pen, Kim with camera, watching, listening. The clay, the stump, the children, the canvas, the sunlight mingle, transform. Clay breaks apart, comes together. Arms and hands and clay pound, struggle, strain, push, pull. Time slows, sunlight ebbs. Child sounds, clay sounds, stump sounds, pauses, silences ... it is done. The children are gone, and Lexie, Kim, clay, canvas, stump, clipboard, and camera are left with the waning light. We notice the silence and are unwilling to shatter it.

As we sat in the atelier with camera and clipboard, we became co-researchers, noticing, listening, attending to the small gestures, the motion, the stillness, the sounds. We were mesmerized by this clay/stump/canvas encounter; the room reverberated with intensities even after the children had left. The tools we each used, camera and pen and clipboard, provoked different ways of seeing, different ways of thinking. Revisiting our notes and photos invited new conversations, new kinds of questions, and disrupted old habits of thought. This vignette depicts a coming together, a moment in which we, Kim and Lexie, sensed new understandings of who we could be. We continued to discuss this encounter for months, and the reverberations of our collaborative reflections seeped into our pedagogies. Our questions and wonderings led to further questions, inspiring us into further research and experimentation. Our work together as pedagogical leaders began.

\section{Pedagogical Leaders as Co-researchers: Kim}

Prior to these moments in the atelier, we had focused on what an atelier could look like, what materials it might hold, what engagements might take place. After this clay/stump/canvas encounter, space opened in which to discuss materiality and the intersections and interconnections of child/bodies/clay/voice. We explored gender, routines, and more. I could pose new questions:

What are the children doing? What are the materials doing?

What happens when we shift from focusing only on what the child does, says, or learns and begin to attend to what happens between the child, the material, the space?

What questions do we have about this encounter?

How do our questions shape what we see? How can we be more intentional with our questions?

How do discourses of gender and power contribute to how the children acted?

How might we challenge normative understandings of early years pedagogy to examine and complexify our perceptions of gender and power?

My role as pedagogical facilitator took on a vibrancy as I was no longer the stranger. "Putting into question" was now a dynamic push and pull between trusting colleagues. We delved into new dialogues, examining practices that were habituated, digging into histories and assumptions of childhood and who/what educators could be. The process of documenting the clay/stump/canvas/child encounters and creating a pedagogical narration was central to this opening for dialogue. 


\section{Creating a Culture of Dialogue: Lexie}

I began sharing narrations of moments in the atelier with educators in my centre, and in doing so, opened myself to vulnerability. By taking on the role of director/leader as researcher, I put aside the role of director/leader as expert and opened spaces for uncertainty and reflective dialogue. I tried to resist conventional ideas of leadership that presume I ought to have all the answers. In being vulnerable and rejecting certainty, I hoped that what had previously been unspoken could now be discussed and we could dig deeper, take risks, engage in dialogue, and challenge our pedagogy.

One of our biggest tensions was around the communication books in which educators wrote an entry for every child on sleep and toileting, along with an anecdote about the child's day. Educators were required to write during nap time, which was also their time to clean and eat. There were mixed feelings among educators. They knew how important the books were to families, but were frustrated that the books were focused only on tracking bowel movements and sleep schedules. They wanted to begin writing pedagogical narrations which they felt might make visible the complexity of their work. However, some educators and most families placed great value on the books and were adamant that they should continue as they were. Being able to talk with me about what they were feeling, and their tensions, was not easy for them. I worked to create a safe place for everyone to voice their thoughts and opinions without consequence, and proposed a vote. The communication books were voted out, and I supported the decision. Some hard feelings ensued, and some educators remained disappointed with the decision. However, deeper conversations and collaboration gradually started to occur. I feel that through this process, mutual respect has emerged, allowing both me and my staff to ask questions and consider possibilities. The educators seem to feel safe to make mistakes without the consequence of losing their jobs. I have noticed that they are more open to challenging the "shoulds" of the daycare by trying out new ideas and pushing boundaries.

Once the communication books were gone, educators used the quiet time to chat and make notes while cleaning. They took turns doing chores to allow their colleagues to work on the computer. Conversations and collaboration started to happen as educators began to research more about their observations. They started remembering moments that they shared throughout the day, each giving input and creating more and more dialogue. The educators were going home and writing at night! They sent me their narrations to print, and started producing one a week, two a week, sometimes more! They were sharing their work with their colleagues and at the learning circles we attended every month with Kim.

Outside the entrance to the toddler centre, I installed a sandwich board on which to post narrations. I planted wisteria bushes beside the boards. I brought in potted plants, and my husband made two curved wooden benches where families could sit and read the narrations. The educators could not wait to display what they had been so carefully working on, and quickly one board became two boards. A buzz began to grow among the families. Parents wanted copies of the narrations, and educators were excited to share their work and talk about their observations. Setting aside the image of the director as the person with all the answers and instead engaging in open dialogue alongside educators in my centre was, at first, unsettling. It requires me to share my vision with the educators but remain open to their visions as well. I invite dialogue, yet these dialogues bring tension, discomfort. However, I believe these dialogues and tensions have worked to strengthen the bonds among all of us, educators and myself. Our care, trust and respect run deep. Thinking together is part of our culture, and my role as pedagogical leader is rich with possibility.

\section{Living in Question: Kim}

The role of the pedagogical facilitator is to be the outsider who poses reverberant questions (Vintimilla, 2016). As 
an outsider, I am not an expert, but neither am I a colleague or a peer. My questions do not have to be acted upon: they may be pushed aside or taken up; they may provoke anger or disruption; they may be welcomed or shunned. But whatever the response, the questions hover and aim to defamiliarize the familiar. Questions have the potential to crack certainties and, once cracked, these certainties may slowly, gradually crumble.

I noticed the communication books very soon in my visits to the centre. The concept of writing daily about children's sleeping and eating habits seemed to me to reduce educators to custodians who simply managed children. However, I understood that the books had a long history in the centre and that some educators and most families placed great value on the books. To pose questions about the communication books was to cast doubt on a tradition cherished by many. I began the process of defamiliarizing that which is familiar by asking: What if? What else might be possible? I left these questions to hover, then posed them again. Months went by without discussion of the communication books, and we discussed other ideas, other questions. Then I would ask about the books again. Question, pause, question again. My intention was not to instruct educators on the "right" way of communicating with families, nor did I have a specific outcome in mind. Rather, I was interested in questioning the meanings implicit in writing in the communication books. I wondered if the communication books might be placing children as passive receivers of care and placing educators in positions of simply managing bodily functions. The conversation around the communication books entwined with other questions, other practices, other shifts. A culture of research began to emerge, and two years after I posed the first question about the books, the educators chose to eliminate them.

The process by which the communication books were eliminated was not linear, prescriptive, or a predetermined goal. Rather, it was one thread in ongoing conversations about possibilities for thinking differently. Eliminating the books was one shift among many shifts, as questioning and critical reflection became a way of being. Practices that had been assumed to define quality came into question, and certainties were unsettled.

\section{Reimagining Pedagogical Leadership}

Throughout our work, we continue to consider how pedagogical leadership might be imagined and how this leadership might be enacted in ways that resist hierarchical relations and embrace an ethic of uncertainty. By putting moments of daily practice into question and by acknowledging this process as enacting leadership, we resist the leader/follower binary. In this way, leadership becomes an everyday event through the work of educators.

Our, Kim and Lexie's, work together has been dialogic, relational, and informed by lived experience. Questions flourish in spite of the discomfiture they draw, because we have established trust and a willingness to be imperfect. Dissensus is perceived, not as a barrier, but as an asset to generate further conversation. Having brought into existence a mode of relations that valued the push and pull of ideas and a willingness to be uncertain, we could then extend this mode with educators. Hierarchies became flattened as educators recognized that dialogue, experimentation, and dissensus were not only accepted, but welcomed. New ideas about practice could be imagined, acted upon, and discussed. Some of these ideas created tensions, rifts, and complaints or drew the ire of families and educators, resulting in intense and uncomfortable dialogue spanning weeks or months. Other ideas opened joyful and lively conversations and deepened relations among families, educators, and children. There was always a sense that the door was open for discussion.

Time is of consequence in these processes of pedagogical leadership. We have allowed time for ourselves to build trust, time to simmer with questions and theoretical perspectives. We know that we all come to this work with histories, certainties, and understandings, and we need time to share these, to deconstruct them, and to trust that risking experimentation can be generative. Our work together has been rich and satisfying, difficult and tense. We 
have stumbled and faltered, and have thrilled and flourished. There were times when nothing seemed to happen and times when everything was bursting with promise. This tangled tale of our pedagogical leadership is not done: We continue to wonder, hope, and experiment, yet we really do not know what will happen next. We live with questions, and we cannot predict where they will take us. For us, it is enough to live with the joys and tensions that questions invite, the delight of "what ifs" in our always becoming roles as pedagogical leaders.

\section{References}

Berger, I. (2015). Pedagogical narrations and leadership in early childhood education as thinking in moments of not knowing. Canadian Children, 40(1), 130-147

Canadian Council of Ministers of Education. (2014). CMEC early learning and development framework. Retrieved from https://www. cmec.ca/Publications/Lists/Publications/Attachments/327/2014-07-Early-Learning-Framework-EN.pdf

Dahlberg, G., \& Moss, P. (2005). Ethics and politics in early childhood education. New York, NY: Routledge.

Government of Canada. (2017). Multilateral early learning and child care framework. Retrieved from https://www.canada.ca/en/ employment-social-development/programs/early-learning-child-care/reports/2017-multilateral-framework.html

Government of Ontario. (2017). Ontario renewed early years policy framework. Retrieved from http://www.edu.gov.on.ca/childcare/ renewed_early_years_child_care_policy_framework_en.pdf

Krieg, S., Davis, K., \& Smith, K. A. (2014). Exploring the dance of early childhood educational leadership. Australasian Journal of Early Childhood, 39(1), 73-80.

Langford, R. (2006). Discourses of the good early childhood educator in professional training: Reproducing marginality or working toward social change. International Journal of Educational Policy, Research, and Practice, 7(1), 115-125.

Murray, J., \& Clark, R. M. (2013). Reframing leadership as a participative pedagogy: The working theories of early years professionals. Early Years, 33(3), 289-301. doi:10.1080/09575146.2013.781135

Osgood, J., \& Giugni, M. (2015). Reconfiguring "quality": Beyond discourses and subjectivities to matter, bodies, and becomings in early childhood education. In G. S. Cannella, M. S. Pérez, \& I. F. Lee (Eds.), Critical examinations of quality in childhood education and care: Regulation, disqualification, and erasure (pp. 139-156). New York, NY: Peter Lang.

Pacini-Ketchabaw, V., Nxumalo, F., Kocher, L., Elliott, E., \& Sanchez, A. (2015). Journeys: Reconceptualizing early childhood education practices through pedagogical narration. Toronto, ON: University of Toronto Press.

Pacini-Ketchabaw, V., \& Pence, A. (2010). Investigating quality early learning environments project, Phase II, 2009-2010: Final report. Retrieved from https://static1.squarespace.com/static/55ab27f3e4b048cfaclc647a/t/58bfbda1f7e0abb09 dd89660/1488961018413/100727_IQP2_maint_report_June_2010.pdf

Sinha, M. (2014). Results from the general social survey: Child care in Canada. Retrieved from http://www.statcan.gc.ca/pub/89-652-x/89652-x2014005-eng.pdf

StrongStart BCEarly Learning Programs. (2008). Operations guide. Retrieved from http://www2.gov.bc.ca/gov/content/educationtraining/ administration/kindergarten-to-grade-12/early-learning/strongstart-bc

Vintimilla, C.D.(2016). Encounters with a pedagogista. Contemporary Issues in Early Childhood,1(1), 1-11.doi:10.1177/1463949116684886

Woodrow, C., \& Busch, G. (2009). Repositioning early childhood leadership as action and activism. European Early Childhood Education Research Journal, 16(1), 83-93. doi:10.1080/13502930801897053

Young, C. (2007). Professional leadership in early childhood education: A summary of University of Victoria, British Columbia, Investigating Quality (IQ) early learning framework proposal and three international models: New Zealand, United States, United Kingdom. A discussion paper for ECEBC board of directors. Retrieved from http://www.ecebc.ca/leadership/files/Discussion_Paper.pdf 